\title{
К ВОПРОСУ О НРАВСТВЕННЫХ ОСНОВАНИЯХ ПРИНЦИПОВ ПРАВА
}

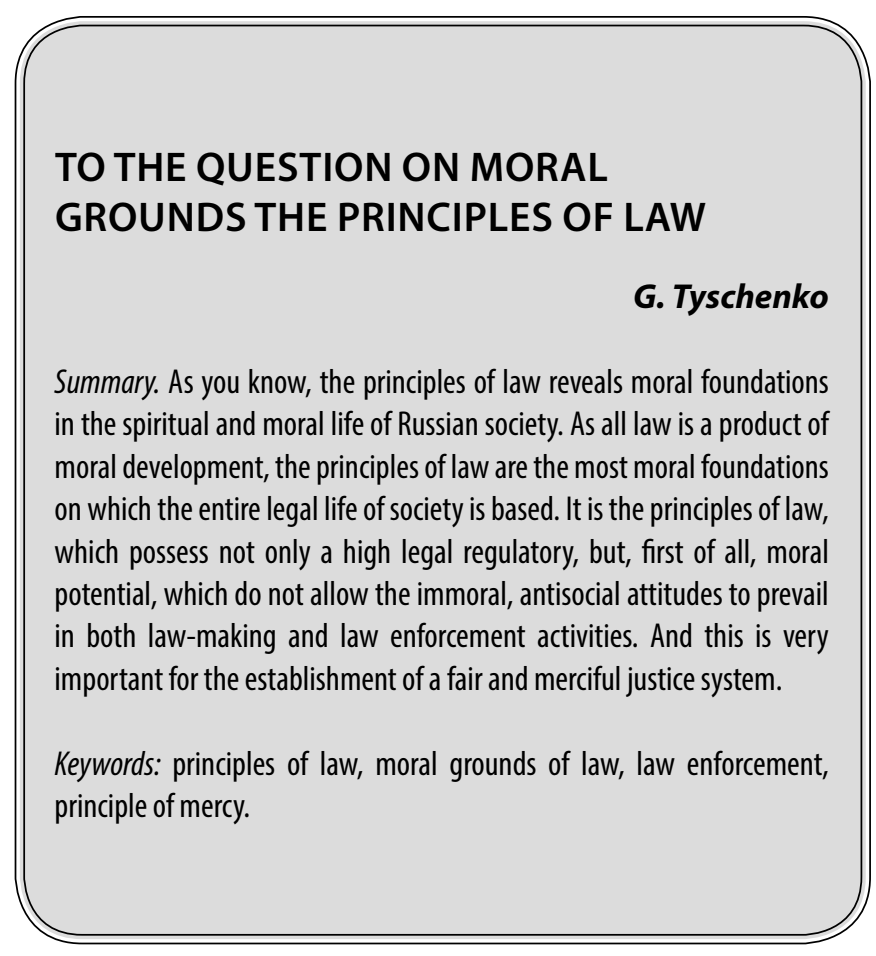

B науке теории государства и права не полностью освещён подход к изучению нравственно-правовой природы принципов российского права, хотя именно нравственная сущность данного правового явления имеет, на наш взгляд, основополагающее значение для правового регулирования общественных отношений в области частных и публичных отраслей российского права.

Принципы российского права пропитаны нравственным содержанием. В них сконцентрированы нравственные постулаты, нередко способные ещё в большей степени чем законы и содержащиеся в них нормы права, побудить человека на совершение тех или иных действий или квоздерживанию от определенной модели поведения. Следует согласиться с исследователем вопроса о соотношении морали и нравственности И.О. Исмаиловым, что высокоморальная личность не будет слепо подчиняться закону, а проведёт их содержание через собственную моральную оценку. Такой человек может внешне подчиниться их требованиям, но будет стремиться к борьбе за их изменение, совершенствование или отмену. Ведь законы в правовом государстве всегда требуют оценки под углом зрений о понятии нравственности и справедливости. Существует мнение, что стремление организовать общественную жизнь только с точки зрения лишь правовых норм, жёсткая правовая регла-

\author{
Тыщенко Глеб Валерьевич \\ Аспирант, ФГБОУ ВО «Алтайский государственный \\ университет», г. Барнаул \\ gleb.tyshchenko.2017@mail.ru
}

Аннотация. Как известно принципы права обнаруживают нравственные основания в духовно-нравственной жизни российского общества. Как и всё право является продуктом нравственного развития, так и принципы права являются в наибольшей степени нравственными основами, на которых базируется вся правовая жизнь общества. Именно принципы права, обладающие не только высоким праворегулятивным, но, в первую очередь, нравственным потенциалом не дают возобладать безнравственным, антиобщественным установкам в как в правотворческой, так и в правоприменительной деятельности. А это очень важно для становления системы справедливого и милосердного правосудия.

Ключевые слова: принципы права, нравственные основания права, правоприменительная деятельность, принцип милосердия.

ментация жизнедеятельности человека и общества является способом создания тоталитарного государства [4]. Принципы права, как представляется, не сводимы всецело к нормам права и способны дать правотворцу и правоприменителю ориентир для создания и применения нравственно-ориентированного законодательства, отвечающего внутренним представлениям большинства членов российского общества. Конечно, нормы права играют важную роль в регулировании общественных отношений, но вместе с тем их содержание должно согласовываться с принципами российского права, которые имеют значение основополагающих нравственных ориентиров.

Известно, что принципы права не всегда фиксируются в письменном виде. Принципы права могут выводиться из смысла и содержания правовых норм, а также по мнению исследователей принципы права могут вообще существовать лишь в общественном правосознании. В этом смысле принципы права имеют определённое сходство с нравственными нормами. Принципы права не всегда фиксируются в письменном виде и этим они совпадают с нравственными постулатами, не выраженными и в праве. «Нравственность обычно не имеет определённой письменной и систематизированной формы выражения, она не подконтрольна воле законодателя, а возникает и существует в сознании людей в виде со- 
циально-полезного опыта и наследия» - указывает Ю.В. Костин [5].

Многие принципы права содержат в себе нравственную составляющую. Рассмотрим их более подробно. В качестве примеров правовых принципов рассмотрим принцип справедливости, принцип законности и принцип милосердия.

Начнём с принципа справедливости, ведь данный принцип права наиболее полно отражает в себе нравственную составляющую современного российского права.

Следует отметить, что понятие справедливости является по своей сути понятием многоаспектным. Так, по мнению П.П. Баранова и А.П. Окусова право призвано быть выразителем справедливости, а их взаимосвязь отражается уже в самой терминологии: право - правое дело, правда, а «юстиция» в переводе с латинского означает справедливость» [2]. «Представляется, что справедливость имеет комплексный характер и триединую сущность: социальную, духовно-нравственную и юридическую» - справедливо указывает Романец Ю.В [8]. А Е. А. Лукашёва утверждает, что «эта категория (справедливость) подчас объясняется этиками как специфически моральная, а юристами как специфически правовая». Причём как указывают многие авторы в характеристике категории справедливости именно нравственный элемент является первичным, основным, а уже от него отталкиваются социальные и юридические элементы. И это происходит не случайно, а имеет свои глубинные истоки, на что в первую очередь должен обращать внимание любой грамотный правоприменитель. Именно исследование нравственной природы принципа справедливости должно первоначально лежать в основе научной и правоприменительной деятельности, а затем на основании нравственной составляющей следует обращать внимание на юридический аспект. Необходимо помнить, что получая своё закрепление в действующем законодательстве, принцип справедливости имеет истинно нравственно правовой характер. И этому есть обоснованные подтверждения [6].

Так, несмотря на то, что с чисто с юридической точки зрения, с которой принцип справедливости и саму справедливость рассматривают многие ныне действующие правоприменители, основное её свойство, качество, заключается в том, что только она в полной мере способна выступать в качестве необходимой меры соотношения требования одной стороны и воздаяния, наносимого другой стороне. Данной мерой на сегодняшний день проводятся в соответствие интересы индивидов, групп и общества (государства) в целом, а также приводится в соответствие степень защищённости их интересов. Сле- дует согласиться с Олениным О.О. считавшим: «в каждой отрасли права эта мера является целью и предметом поиска, воплощённым в нормах конкретной отрасли права (трудового, гражданского, уголовного и др.)» [8]. Однако в данном случае мы учтём лишь сухой позитивистский аспект принципа справедливости, но не раскроем его настоящую, глубинную сущность. Принцип справедливости не сводим исключительно к юридическому воздаянию за содеянное, равномерное распределение социальных благ. «Крайне вредно «отрывать» справедливость от морально-нравственных оснований и приравнивать её к простой эквивалентности в процессе распределения материальных и социальных благ или же к комбинации моделей формального равенства и неравенства, присущих правовой действительности» - обоснованно отмечает в своей статье Чечельницкий И. В. Опираясь на предшествующий политико-правовой опыт российского государства он также указывает следующее: «справедливость - нравственное понятие, уходящее своими корнями в догосударственный и доправовой период развития нашего общества». «Уже поэтому она не может быть опосредована рамками исключительно правовой материи». И действительно, справедливость, имеющая в своём составе корень «правда» не может быть связана исключительно с юридической позитивистской соизмеримостью. Она лежит гораздо глубже - в нравственных представлениях русского общества о справедливости, сохранившихся и по сей день. А это правоприменитель обязан безусловно учесть.

Правоприменитель обязан помнить, что принцип права - это не математически выверенная мера возмездия за злодеяние или соответствующим образом подсчитанная мера поощрения за благодеяние, но в первую очередь категория нравственности. Право, правда, справедливость, по сути, есть однокоренные слова и пропитаны духовно-нравственным оттенком. Сухой, позитивистский подход к рассмотрению справедливости приведёт к невозможности правильного его применения. На взаимосвязь справедливости и права обратил наше внимание Чичельницкий И.Н. По мнению автора работы: «справедливость и право находятся в диалектической взаимосвязи: закреплённая в праве справедливость получает свойство нормативности, а право тем самым становится справедливым и нравственно обоснованным». «Правовое регулирование общественных отношений посредством справедливого законодательства позволяет добиться социальной справедливости, а закрепление нравственного принципа справедливости в праве модифицирует его в нравственно-правовой императив» - подытоживает автор [9].

Вместе с тем правоприменителю надлежит помнить о том, что само закрепление данного принципа в Конституции, отраслевом кодексе, законе ещё не делает 
закон справедливым. Реализация принципа справедливости - это его реализация в первую очередь в нравственном ключе и большая работа по приведению в соответствие данного принципа с нормами российского права. Как указывает автор: «необходимо понимать, что с одной стороны, если слово «справедливость» не фигурирует в конструкции правовой нормы, это не значит, что она несправедлива, а с другой стороны, если слово «справедливость» присутствует в законе, то он не становится справедливым априори, поскольку требуется также поступательная реализация принципа справедливости в каждой его статье» [9].

Раскрывая правовой принцип законности суду надлежит иметь ввиду следующее. «Большинство юристов в настоящее время признают сложный характер законности». «Разносторонний и многоплановый подход к определению законности находит поддержку у многих исследователей» [3].

На мой взгляд, говорить о том, что законность и принцип законности трактуются лишь в духе беспрекословного позитивистского подчинения граждан любым законам государства не представляется возможным. Адекватным образом трактовка принципа законности отражена в определении Витрука Н.В., который под законностью понимал: «идею, требование и систему (режим) реального выражения права в законах государства в самом нормотворчестве». Данное определение особо выделяет в своей работе Долгопят А.О. [3]. В связи с этим следует определить, что законы должны соответствовать самому праву, его духу и нравственному содержанию, в которых учитываются и наиболее целостно взаимодействуют интересы личности, общества и государства. Закон должен отражать, дух, глубинную природу права, способствующего удовлетворению насущных потребностей человека и способствующего прогрессивному развитию общества. В этом смысле и вся система законов должна соответствовать по духу глубинному, естественному праву и, на мой взгляд, ни один из законов и подзаконных актов: указов, постановлений и других, не должен ему противоречить.

Принцип милосердия - важнейший естественно-правовой принцип также не в полной мере оценённый правоприменителем. В современном праве принцип милосердия чаще упоминается под названием принцип гуманизма, но это не отражает его сути применительно к российскому праву и не характеризует специфику милосердия. Само по себе милосердие по мнению Е.М. Березиной, рассматривающей этот феномен с морально-этической, биологической, культурной, исторической и антропологической сторон «представляет собой нравственную и гуманистическую традицию, возникшую в процессе формирования че- ловеческого общества и становления основных социальных институтов» [2]. Далее автор акцентирует наше внимание на самой сущности, глубинной природе принципа милосердия, которая заключается в следующем. Как считает исследователь: «попытки определения истоков милосердного отношения к другим приводят нас к проблеме рождения «человечности» как таковой, которую вслед за российским исследователем В.Д. Шадриковым, мы понимаем как комплекс качеств человека, определяющих его отношение к другим людям, и в действиях и поступках, характеризующихся с позиций добра и зла» [10].

Таким образом принцип милосердия в своей основе также несёт серьёзный нравственный заряд, призванный обеспечивать последующую деятельность всей системы российского права. Но милосердия, не только важнейший нравственный принцип не позволяющий праву скатиться в бездну зла, но и важный духовно-религиозный принцип, что также необходимо помнить исходя из истории нашего народа и сегодняшней приверженности многих наших к граждан к православному религиозному культу. «Христианское учение возводит милосердие в ранг предельного нормативного основания». Здесь милосердие- универсальное требование, основанное на понимании общности людей в любви, и эта любовь ко всем и даже шире (в том числе и к среде обитания) наделена ощущением ценности бытия.

Принцип милосердия является основополагающим принципом права, базирующимся на нравственной и религиозной традиции. Для правоприменителя это особенно важно знать, поскольку в сфере правоприменительной деятельности данный принцип обозначает необходимость уважительного, сострадательного отношения к лицу, попавшему в орбиту правоотношения. При этом данное отношение должно распространиться на всех без исключения участников правоотношения, а не только на лицо, которое на первый взгляд является пострадавшей стороной в сфере публично-правовых и частно-правовых отношений. Цель принципа милосердия, на наш взгляд, заключается во всесторонней оценке правового положения субъекта права, необходимости обеспечения его безопасности, более глубинного изучения его экономического, политического, социального и правового статуса для выявления смягчающих обстоятельств и учёта его интересов.

Таким образом, законодателю и правоприменителю в своей деятельности следует учитывать, что принципы права не сводятся всецело к правовым нормам, а основаны на нравственных постулатах, не всегда закреплённых в текстах нормативно-правовых актов, но оказывающих существенное влияние на развитие права. 


\section{ЛИТЕРАТУРА}

1. П.П. Баранов, А.П. Окусов Аксиология юридической деятельности. Учебное пособие / Баранов П. П., Окусов А. П. — Ростов-на-Дону: РЮИ МВД России, 2003. - $364 \mathrm{C}$.

2. Березина Е.М. К вопросу о генезисе нравственного принципа милосердия//Е.М.Березина/Вестник московского государственного университета культуры и искусств.-№ 5-2011.—с. 44

3. Долгопят А. О. Понятие и содержание принципа законности//А.0. Долгопят/Бизнес в законе. Экономико-юридический журнал. -№ 4. - 2008. - c. 243.

4. Н.О. Исмаилов. Взаимосвязь права и нравственности в контексте справедливости/ Исмаилов Н. 0.// Вестник Адыгейского государственного университета. Серия 1: Регионоведение: философия, история, социология, юриспруденция, политология, культурология.— 2014 г. — c. 15-22

5. Ю.В. Костин. Проблема соотношения права и нравственности в современной юридической науке/Костин Ю.В//Ученые записки Орловского государственного университета. Серия: Гуманитарные и социальные науки. - 2008 г. - с. 218

6. Е.А. Лукашёва. Право, мораль, личность / Лукашева Е. А.; Отв. ред.: Чхиквадзе В. М. - М.: Наука, 1986. - с. 23

7. Оленин Н. Н. Принцип справедливости и право РФ.//Н.Н. Оленин/Вестник Томского государственного университета.-№ 332. — 2010. — c. 111-112.

8. Романец Ю. В. Этические основы права и правоприменения.-М.: ИКД «Зерцало-М», 2012.—c. 11.

9. Чечельницкий И. В. Принцип справедливости в российском праве//И.В. Чечельницкий/Социально-экономические явления и процессы. 一 № 7.—- 9 . 2014.- c. 101.

10. Шадриков В.Д. Происхождение человечности: (учебное пособие для студентов высших учебных заведений)//В.Д.Шадриков/ -М.: Издательская корпорация «Логос», 1999.— — 59.

с Тыщенко Глеб Валерьевич ( gleb.tyshchenko.2017@mail.ru).

Журнал «Современная наука: актуальные проблемы теории и практики»

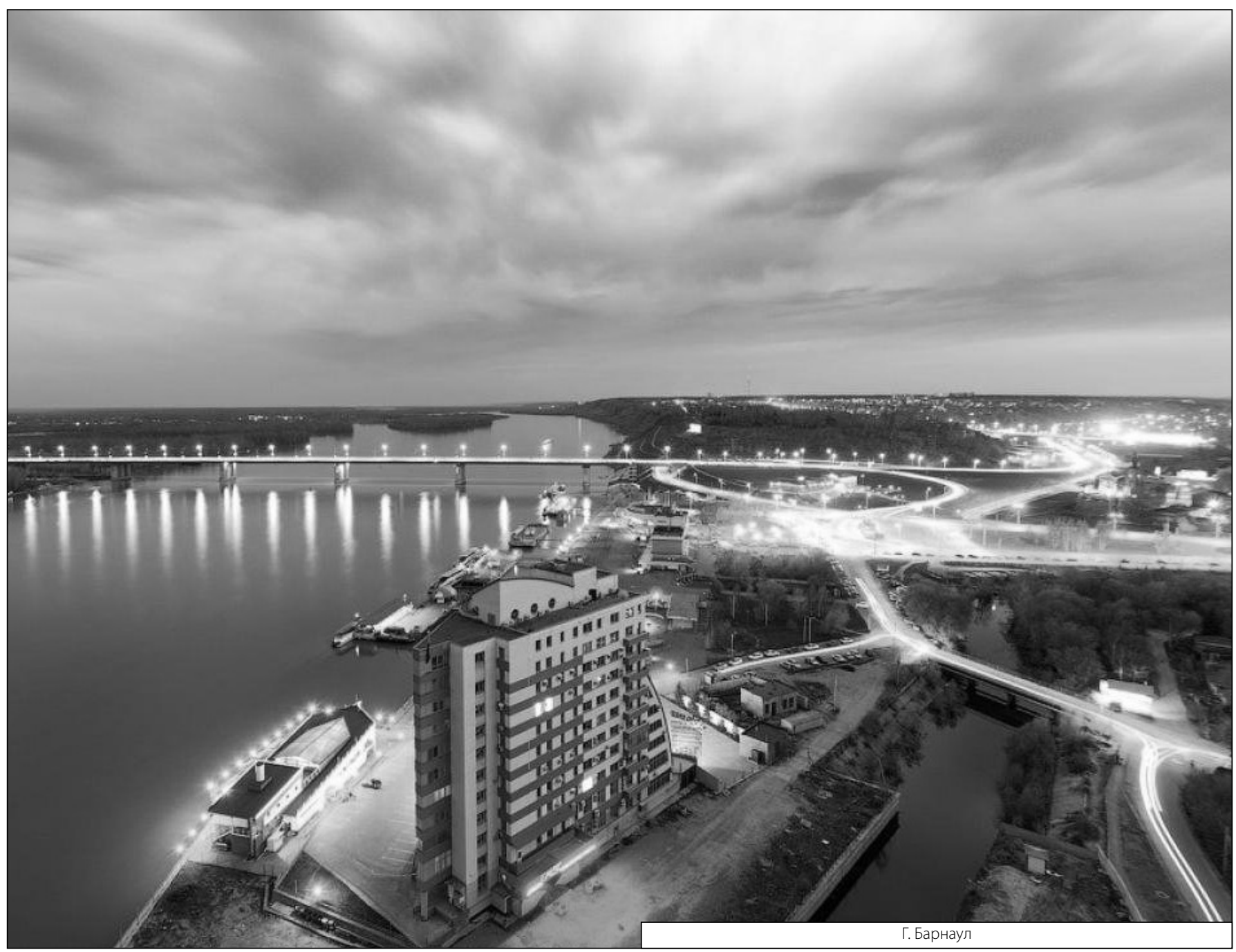

